\title{
Effectiveness of gutta-percha and Resilon in filling lateral root canals using the Obtura II System
}

\section{Mario Tanomaru-Filho(a) Arnaldo Sant'anna-Junior (a) Roberta Bosso(a) Juliane Maria Guerreiro- Tanomaru(a)}

(a) Department of Restorative Dentistry, Faculdade de Odontologia de Araraquara, Unesp - Univ Estadual Paulista, Araraquara, SP, Brazil.
Corresponding Author:

Mario Tanomaru-Filho

Rua Humaitá, 1901, ap. 182

CEP: 14801-385

Araraquara - SP - Brazil

E-mail: tanomaru@uol.com.br

Received for publication on Dec 20, 2010 Accepted for publication on Mar 29, 2011

\begin{abstract}
The aim of this study was to evaluate the effectiveness of gutta-percha and Resilon in filling lateral root canals by using the Obtura II system. Root canals of artificial teeth were prepared using a standard protocol, and lateral canals were made in three thirds of the root canal. The root canals were filled with either Obtura gutta-percha (OB), Endopoints flow gutta-percha (ED), or Resilon (RE) by using the Obtura II system. The fillings were evaluated using digitized radiographs and analyzed by using Image Tool software. Outlines of the total areas of the lateral canals and the filled areas were used to determine the percentage of filling in each lateral canal. Data were analyzed with the Kruskal-Wallis and Dunn tests at a 5\% significance level. RE and ED showed better results than $\mathrm{OB}$ did in the three thirds of the root canals. When the root canal thirds were compared, OB and RE were more effective in the cervical third than in the apical third $(\mathrm{p}<0.05)$. In conclusion, Resilon and EndoFlow gutta-percha were effective in filling lateral canals by using the Obtura II system.
\end{abstract}

Descriptors: Endodontics; Gutta-percha; Root Canal Obturation; Root Canal Filling Materials.

\section{Introduction}

The main objective of endodontic treatment, in addition to cleaning and shaping the root canals, is to fill the pulp cavity ${ }^{1-3}$ and achieve periapical repair. ${ }^{4,5}$ The filling technique and the properties of the material employed are the two essential factors for three-dimensional filling of the root canal system..$^{6-8}$

It has been suggested that the ideal root canal filling should consist of a sufficient amount of gutta-percha covered by a thin layer of a sealer., ${ }^{9,10}$ In this regard, several filling techniques employing thermoplastic guttapercha have been evaluated for their effectiveness in filling irregular or lateral root canals. ${ }^{9}, 11-14$

Evaluation of thermoplastic root canal filling techniques showed that assessment of the properties of gutta-percha in response to heat is of paramount importance. ${ }^{15,16}$. The thermoplasticity of different types of gutta-percha is affected by their chemical compositions $s^{15,17,18}$ as well as the thermal changes induced during the manufacturing process and the use of these materials. ${ }^{17}$ Although several endodontic techniques have been evaluated with respect to their ability to adequately fill the root canal 
and its irregularities, $, 911,12$ few studies have focused on the thermoplasticity of different brands of guttapercha and Resilon when using thermoplastic techniques. ${ }^{8,19,20}$

Resilon (Resilon Research LLC, Madison, USA), a synthetic polymer-based material, has been proposed as an alternative to gutta-percha. ${ }^{7}$ The thermoplastic properties of Resilon were studied by Miner et al., ${ }^{10}$ who demonstrated that Resilon and gutta-percha have similar melting points of approximately $60^{\circ} \mathrm{C}$. Tanomaru-Filho et al. ${ }^{20}$ evaluated the thermoplastic ability of different gutta-percha cones in comparison with that of Resilon, and they concluded that the latter presented better thermoplasticity than gutta-percha did.

Since the introduction of thermoplastic techniques in $1967,{ }^{4}$ several new devices and materials have been proposed and developed for use with thermoplasticized gutta-percha in root canal fillings. One of these devices was the Obtura II system, which heats and injects the plasticized gutta-percha into the canal ${ }^{5}$. Karr et al. ${ }^{21}$ and Karabucak et al. ${ }^{22}$ observed that both Resilon and Obtura gutta-percha showed similar results when lateral grooves and dentin depressions were filled using the Obtura II system.

In addition to Obtura gutta-percha, other materials have been used with this system. However, few studies have focused on comparing the effectiveness of gutta-percha and Resilon without the use of an endodontic sealer in this technique. ${ }^{7,8}$ The aim of the present study was to evaluate the ability of two types of gutta-percha and Resilon to fill simulated lateral canals with the Obtura II system.

\section{Methodology}

Thirty lower premolar artificial transparent teeth (Odontofix, Ind. e Com. de Mat. Odontol. Ltda., Ribeirão Preto, Brazil) were used.

Instrumentation of the root canals was performed $1 \mathrm{~mm}$ short of the apex by using a rotary system with nickel-titanium files (K3 Endo; Sybron Kerr, Orange, USA). Instrumentation was performed using a crown-down technique, starting at a 0.08 taper and progressing to standardized preparation of the apical portion with a size-35 K3 instru- ment and a 0.04 taper. After each file change, the canals were irrigated with $2 \mathrm{~mL}$ of distilled water and dried with a size-35 paper cone (Dentsply Indústria e Comércio Ltda., Petrópolis, Brazil).

An outlining apparatus (Bio-Art, São Carlos, Brazil) was adapted in order to standardize the preparation of the artificially created lateral canals. Lateral canals were created in the cervical, middle, and apical thirds of the root canal $(4,8$, and $12 \mathrm{~mm}$ from the apex) by using a cylinder-shaped bur with a $0.3-\mathrm{mm}$ active end (ST2 bur; Pluritec, São Paulo, Brazil). The teeth were randomly divided into 3 groups of 10 specimens each, and the canals were filled with the materials presented in Table 1.

The root canals were filled using the Obtura II system (model 823-700) and the evaluated filling materials (Table 1). In all groups, a 25 -gauge needle was inserted up to $3 \mathrm{~mm}$ short of the working length to allow passive and gradual insertion of the obturating material in a single increment. Vertical condensation was then performed using size 4 and 5 Schilder condensers (Odous De Deus Ind. e Com Ltda., Belo Horizonte, Brazil) by filling the canals up to their entrance. The temperature settings, i.e., $150{ }^{\circ} \mathrm{C}$ for Group I and $160{ }^{\circ} \mathrm{C}$ for Groups II and III, were in accordance with those recommended by the manufacturer for each material. All specimens were filled without a sealer since the goal of this study was to analyze the ability of the solid materials to fill the lateral canals.

Radiographs of each tooth were obtained in a buccal-lingual orientation, and the images were then digitized and standardized using Adobe Photoshop software. Next, the digitized images were imported into the Image Tool software (UTHSCSA Image Tool for Windows version 3.0; San Antonio, USA), and the total and filled areas of each lateral canal

Table 1 - Filling materials used in the experimental groups.

\begin{tabular}{c|c|c}
\hline Group & Material & Manufacturer \\
\hline G1 & Obtura gutta-percha & Obtura Spartan, Fenton, USA \\
\hline G2 & $\begin{array}{c}\text { EndoFlow gutta- } \\
\text { percha sticks }\end{array}$ & $\begin{array}{c}\text { Endopoints Indústria e Comércio } \\
\text { Ltda. Paraíba do Sul, Brazil }\end{array}$ \\
\hline G3 & Resilon pellets & $\begin{array}{c}\text { Resilon, Pentron Clinical } \\
\text { Technologies, Wallingford, USA }\end{array}$ \\
\hline
\end{tabular}


were measured in all specimens (Figure 1) to determine the percentage of filling of the lateral canals. The results for all lateral canals were also compared according to their location in the different thirds of the root. Data were analyzed with the Kruskal-Wallis test at a 5\% significance level, and comparisons between groups were performed with the Dunn test.

\section{Results}

Means and standard deviations for the percentage of filled areas in the lateral canals in different thirds of the canal and in the three experimental groups are shown in figure 2. Statistical analysis revealed that, in all thirds of the root canal, Resilon and EndoFlow were more effective in filling the lateral canals than Obtura gutta-percha was $(\mathrm{p}<0.05)$. The filling ability of EndoFlow was similar in the three-thirds of the root canal, whereas Resilon and Obtura gutta-percha performed better in the cervical third than in the apical third $(\mathrm{p}<0.05)$.

\section{Discussion}

Root canal filling techniques performed using thermoplasticized gutta-percha allows the formation of a homogeneous mass that fills the irregularities of the canal. ${ }^{8,19}$ These methods rely on the thermoplastic properties of gutta-percha, which may vary among the different types of commercially available gutta-percha..$^{8,19}$

In this study, artificial lateral root canals were prepared using a bur with a diameter of $0.3 \mathrm{~mm}$. The aim of this study was to compare the plasticity of solid root canal filling materials (gutta-percha and Resilon) used without an endodontic sealer by evaluating the ability of these materials to fill simulated lateral canals. The prepared lateral canals had a larger diameter than that of the anatomical lateral canals found in natural teeth. However, the objective of the study was to compare the plasticity of solid filling materials used without an endodontic sealer.

The results obtained with the evaluated materials - Resilon and EndoFlow gutta-percha - showed that the materials had better filling ability when used with the Obtura II system. The differences observed between the two tested commercial brands

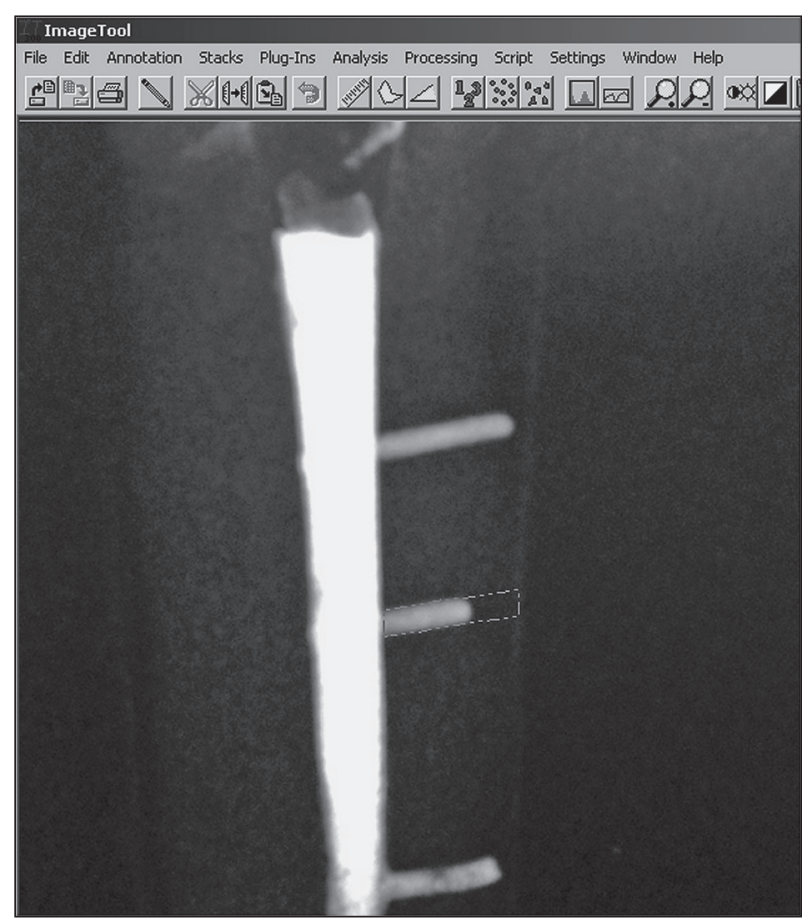

Figure 1 - Measurement of the filled area in the lateral canals by using Image Tool.

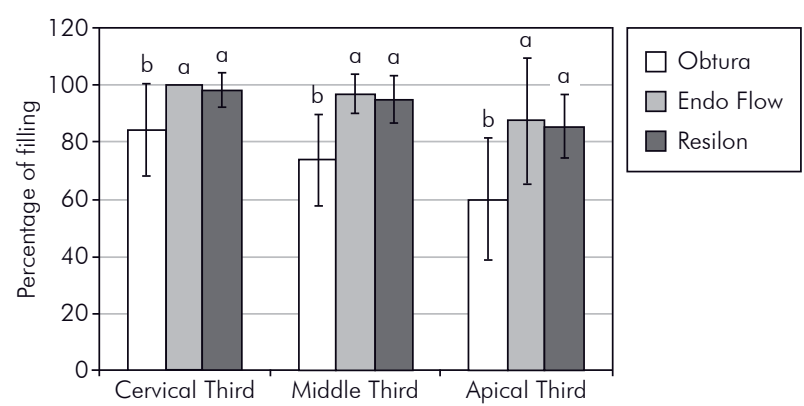

Figure 2 - Mean and standard deviation values of the percentage of filled areas in the lateral canals; the values for different experimental groups and different thirds of the root canal are provided. Means with the same letter $(a, b)$ did not show statistically significant differences $(p>0.05)$.

of gutta-percha may be correlated with the results reported by Gurgel-Filho et al., ${ }^{19}$ who compared the filling ability of five different brands of gutta-percha in lateral canal filling by using a thermomechanical technique and vertical condensation. They concluded that different brands of gutta-percha behave differently during lateral canal filling. Gutta-percha is a natural polymer that undergoes industrial processing and incorporation of other substances before application in dentistry. The thermoplastic proper- 
ties of gutta-percha have been shown to directly depend on its composition and are more pronounced in the pure form than in the commercially available form. ${ }^{17}$ Other studies have reported that the amount of inorganic fillers added to the material, in addition to the thermal changes induced during cone manufacturing, may affect its properties. ${ }^{17,19}$

Tanomaru-Filho et al. ${ }^{20}$ evaluated the thermoplasticity of gutta-percha and Resilon and found that the thermoplasticity of Resilon was greater than that of gutta-percha. Among the gutta-percha cones, Endopoints TP (thermoplastic) had the highest thermoplasticity values, and these values were significantly higher than those for the other tested commercial brands. These results were in agreement with those of this study in which Resilon and one of the gutta-percha brands showed greater filling ability when used with the Obtura II system.

Karr et al. ${ }^{21}$ compared the ability of gutta-percha and Resilon to fill lateral canals and apical depressions using System B in the apical third and Obtura II in the middle and coronal thirds. The authors demonstrated similar results for both materials.

Our results are also in agreement with those of Karabucak et al..$^{22}$ who evaluated the filling ability of the Obtura II and Calamus systems in artificial

\section{References}

1. Akman M, Akman S, Derinbay O, Belli S. Evaluation of gaps or voids occurring in roots filled with three different sealers. Eur J Dent. 2010 Apr;4(2):101-9.

2. Bertacci A, Baroni C, Breschi L, Venturi M, Prati C. The influence of smear layer in lateral channels filling. Clin Oral Investig. 2007 Dec;11(4):353-9.

3. Venturi M, Di Lenarda R, Breschi L. An ex vivo comparison of three different gutta-percha cones when compacted at different temperatures: rheological considerations in relation to the filling of lateral canals. Int Endod J. 2006 Aug;39(8):648-56.

4. Holland R, Manne LN, de Souza V, Murata SS, Dezan Júnior E. Periapical tissue healing after post space preparation with or without use of a protection plug and root canal exposure to the oral environment. Study in dogs. Braz Dent J. 2007;18(4):281-8.

5. Silveira AM, Lopes HP, Siqueira Jr JF, Macedo SB, Consolaro A. Periradicular repair after two-visit endodontic treatment using two different intracanal medications compared to singlevisit endodontic treatment. Braz Dent J. 2007;18(4):299-304. lateral canals created in resin teeth. These authors compared conventional gutta-percha, Flow 150 gutta-percha, and Resilon and demonstrated that the flowability of the material depends more on the properties of the material itself than on the mechanical properties of the obturating systems. Resilon showed better flowability in lateral canals obturated by simple vertical condensation. In this study, the gutta-percha used with the Obtura II system was the conventional Obtura, and not the Flow150 version with enhanced thermoplastic properties. The Obtura gutta-percha was able to fill lateral root canals less effectively than either EndoFlow or Resilon was.

\section{Conclusion}

In conclusion, Resilon and EndoFlow guttapercha are effective in filling lateral canals by using the Obtura II system. However, additional studies comparing Resilon and gutta-percha are necessary to further evaluate the performance of these materials when different thermoplastic filling techniques are used.

\section{Acknowledgements}

This study was supported by a grant from FAPESP (07/00424-4).

6. Gençoglu N, Oruçoglu H, Helvacioglu D. Apical leakage of different gutta-percha techniques: Thermafil, Js Quick-Fill, Soft Core, Microseal, System B and lateral condensation with a computerized fluid filtration meter. Eur J Dent. 2007 Apr;1(2):97-103.

7. Dultra F, Barroso JM, Carrasco LD, Capelli A, Guerisoli DMZ, Pécora JD. Evaluation of apical microleakage of teeth sealed with four different root canal sealers. J Appl Oral Sci. 2006 Oct;14(5):341-5.

8. Tagger M, Gold A. Flow of various brands of gutta-percha cones under in vitro thermomechanical compaction. J Endod. 1988 Mar;14(3):115-20.

9. Jarrett IS, Marx D, Covey D, Karmazin M, Lavin M, Gound T. Percentage of canals filled in apical cross sections - an in vitro study of seven obturation techniques. Int Endod J. 2004 Jun;37(6):392-8.

10. Miner MR, Berzins DW, Bahcall JK. A comparison of thermal properties between gutta-percha and a synthetic poly- 
mer based root canal filling material (Resilon). J Endod. 2006 Jul;32(7):683-6.

11. Bowman C, Baumgartner JC. Gutta-percha obturation of lateral grooves and depressions. J Endod. 2002 Mar;28(3):220-3.

12. Gencoglu N, Yildirim T, Garip Y, Karagenc B, Yilmaz H. Effectiveness of different gutta-percha techniques when filling experimental internal resorptive cavities. Int Endod J. 2008 Oct;41(10):836-42.

13. Carvalho-Sousa B, Almeida-Gomes F, Carvalho PR, ManígliaFerreira C, Gurgel-Filho ED, Albuquerque DS. Filling lateral canals: evaluation of different filling techniques. Eur J Dent. $2010 \mathrm{Jul} ; 4(3): 251-6$.

14. Moraes FG, Bramante CM, Moraes IG, Carneiro E, Menezes R. Influence of the EDTA, Nd:YAG laser and association of both on the filling of artificial lateral root canals. J Appl Oral Sci. 2004 Jan-Mar;12(1):22-6.

15. Kolokuris I, Arvanitoyannis I, Blanshard JMV, Robinson C. Thermal analysis of commercial gutta-percha using differential scanning colorimeter and dynamic mechanical thermal analysis. J Endod. 1992 Jan;18(1):4-9.

16. Tanomaru-Filho M, Silveira GF, Tanomaru JM, Bier CA. Evaluation of the thermoplasticity of different gutta-percha cones and Resilon. Aust Endod J. 2007 Apr;33(1):23-6.
17. Combe EC, Cohen BD; Cummings K. Alpha and beta forms of gutta-percha in products for root canal filling. Int Endod J. 2001 Sep;34(6):447-51.

18. Maniglia-Ferreira C, Silva Jr JB, Paula RC, Feitosa JP, Cortez DG, Zaia AA, et al. Brazilian gutta-percha points. Part I: chemical composition and X-ray diffraction analysis. Braz Oral Res. 2005 Jul-Sep;19(3):193-7.

19. Gurgel-Filho ED, Feitosa JPA, Gomes BPFA, Ferraz CCR, Souza Filho FJ, Teixeira FB. Assessment of different guttapercha brands during the filling of simulated lateral canals. Int Endod J. 2006 Feb;39(2):113-8.

20. Tanomaru-Filho M, Bier CA, Tanomaru JM, Barros DB. Evaluation of the thermoplasticity of different gutta-percha cones and the TC system. J Appl Oral Sci. 2007 Apr;15(2):131-4.

21. Karr NA, Baumgartner JC, Marshall JG. A Comparison of Gutta-Percha and Resilon in the Obturation of Lateral Grooves and Depressions. J Endod. 2007 Jun;33(6):749-52.

22. Karabucak B, Kim A, Chen V, Iqbal MK. The comparison of gutta-percha and Resilon penetration into lateral canals with different thermoplastic delivery systems. J Endod. $2008 \mathrm{Jul} ; 34(7): 847-9$. 